Johnson \& Wales University

ScholarsArchive@JWU

Health \& Wellness Department Faculty

Publications and Research

2014

Availability and range of tobacco products for sale in

Massachusetts pharmacies

Andrew B. Seidenberg

Weiwei Hong

JiaYue Liu

Jonathan K. Noel

Vaughan W. Rees

Follow this and additional works at: https://scholarsarchive.jwu.edu/health_fac

Part of the Medicine and Health Sciences Commons 


\title{
Availability and range of tobacco products for sale in Massachusetts pharmacies
}

\author{
Andrew B Seidenberg, Weiwei Hong, JiaYue Liu, Jonathan K Noel, Vaughan W Rees
}

Center for Global Tobacco Control, Department of Society, Human Development and Health, Harvard School of Public Health, Boston, Massachusetts, USA

\section{Correspondence to} Dr Vaughan Rees, Center for Global Tobacco Control, Department of Society, Human Development and Health, Harvard School of Public Health, Kresge, 6th Floor, 677 Huntington Avenue, Boston, MA 02115, USA; vrees@hsph.harvard.edu

Received 21 May 2012 Accepted 10 October 2012 Published Online First 8 November 2012

\begin{abstract}
Objective New tobacco control policies have been introduced in Massachusetts which restrict tobacco product sales in pharmacies. The purpose of this investigation was to outline the scope of pharmacy involvement in the tobacco market by assessing the availability and range of tobacco products sold in Massachusetts pharmacies.

Methods Public listings of licenced pharmacies and tobacco retailers in Massachusetts were examined to determine the proportion of pharmacies licenced to sell tobacco, and the proportion of tobacco retailers possessing a pharmacy licence. Telephone interviews were conducted with a random sample $(n=70)$ of pharmacies possessing a tobacco licence to assess the availability and range of tobacco products for sale. The availability of nicotine replacement therapy (NRT) products was assessed as a comparison.

Results The majority of pharmacies in Massachusetts
\end{abstract} possessed a tobacco licence (69\%), and pharmacies made up $9 \%$ of licenced tobacco retailers. Among pharmacies surveyed that reported selling tobacco (90\%), cigarettes were the most available tobacco product for sale (100\%), followed by cigars (69\%), little cigars/ cigarillos (66\%), moist snuff (53\%), pipe tobacco (49\%), roll-your-own tobacco (34\%), snus (14\%), dissolvable tobacco $(11 \%)$ and electronic cigarettes $(2 \%)$. Nearly all pharmacies selling tobacco offered the nicotine patch (100\%), gum (100\%) and lozenge (98\%).

Conclusions Tobacco-free pharmacy policies would affect a majority of Massachusetts pharmacies and remove a variety of tobacco products from their store shelves. Further, nearly one in ten tobacco retailers would be eliminated by prohibiting tobacco sales in Massachusetts pharmacies statewide.

\section{INTRODUCTION}

In recent decades important changes have been observed in the sale of tobacco products in pharmacies. Internationally, the sale of tobacco products in pharmacies has been eliminated in many developed countries ${ }^{1} 2$ and Federation Internationale Pharmaceutique, an international pharmacists' organisation, has lent support to tobacco-free pharmacy policies. ${ }^{3}$ Data from developing countries are rare, but one recent study has suggested that just $5.7 \%$ of pharmacies in Guatemala sell tobacco products. ${ }^{4}$ Concern over pharmacy sale of tobacco in the USA has led to the introduction of new local tobacco control policies. In 2008, San Francisco became the first American city to prohibit pharmacies from selling tobacco products. ${ }^{5}$ Boston adopted a similar policy in 2009. ${ }^{6}$ In both jurisdictions, restrictions apply to all businesses with a pharmacy licence, including large wholesale stores and grocery stores that contain pharmacies. Since this time, additional communities in Massachusetts have prohibited tobacco sales in pharmacies, including the city of Newton and the town of Needham (personal correspondence (AS), Municipal Tobacco Control Technical Assistance Program).

Pharmacies have been targeted for tobacco sales restrictions due to their important role in supplying health-related products and services. Pharmacies are the leading distributors of medications used to treat and manage tobacco-related diseases, including chronic obstructive pulmonary disease, heart disease and nicotine dependence. ${ }^{7}$ In 2004, US expenditures for smoking-attributable prescription drug sales totalled $\$ 15.5$ billion, or $9.48 \%$ of total prescription drug sales. ${ }^{8}$ Further, ancillary health services, including smoking cessation counselling by pharmacists or other trained clinicians, are increasingly offered within pharmacies. $^{9} 10$ Pharmacist-led cessation counselling has been recognised as having many advantages, including pharmacists' unique expertise in drug therapy and broad access to the public. ${ }^{11}$

The pharmacist community has held a longstanding position against the sale of tobacco products in pharmacies. In 1971, The American Pharmaceutical Association, now the American Pharmacists Association, passed a resolution recommending that tobacco products not be sold in pharmacies. ${ }^{12}$ Several state pharmacist associations have also expressed opposition to pharmacy tobacco sales. ${ }^{13} 14$ Surveys of pharmacists and pharmacy students reveal discontent regarding the sale of tobacco in their workplaces. $^{15-18}$ Further, in 2010, the American Pharmacists Association adopted a newer resolution encouraging the government to end reimbursements to pharmacies selling tobacco and to stop licensing pharmacies that sell tobacco. ${ }^{19}$

Nevertheless, many American pharmacies sell tobacco products. A 1996 national survey found that half $(50.5 \%)$ of pharmacies sold cigarettes. ${ }^{20}$ Surveys conducted in Kentucky and California have reported between $33-61 \%$ of pharmacies sell cigarettes. $^{21-23}$ These surveys also found that independently-owned pharmacies are less likely than chain pharmacies to sell tobacco products. Further, new evidence has revealed that despite a national declining trend in total cigarette sales in the USA, cigarette sales in pharmacies have increased in recent years. ${ }^{24}$

As tobacco sales in pharmacies face increased scrutiny and more communities consider restrictions, data on the availability and range of tobacco 
products sold in pharmacies are needed to help inform policymakers of the scope of pharmacy involvement in the tobacco market. Such data may also help elucidate the potential impact of tobacco product sales restrictions. The purpose of this investigation was to use publicly available data to determine the proportion of pharmacies that possess a tobacco licence, the proportion of tobacco retailers that possess a pharmacy licence and the types of tobacco products sold in pharmacies in Massachusetts.

\section{METHODS}

A cross-sectional, descriptive study was conducted to determine: (i) the proportion of licenced pharmacies in Massachusetts which also possess a licence to sell tobacco products; (ii) the proportion of licenced tobacco retailers in Massachusetts which also possess a pharmacy licence; and (iii) the availability (\% pharmacies which carry tobacco products) and range of tobacco products sold among a subset of Massachusetts pharmacies. The availability of nicotine replacement therapy (NRT) products was also determined for comparative purposes.

Public listings of licenced retail pharmacies $(n=1133)$ and tobacco retailers $(n=8840)$ in Massachusetts were obtained from the Massachusetts Department of Public Health and Massachusetts Department of Revenue, respectively, in February, 2010. By March, 2010, four communities in Massachusetts (Boston, Needham, Newton, and Uxbridge) had adopted tobacco-free pharmacy policies (personal correspondence (AS), Massachusetts Department of Public Health). Pharmacies located within these jurisdictions $(n=123)$ were excluded. The two lists were compared by business address to determine the proportion of pharmacies possessing a tobacco licence and the proportion of tobacco retailers possessing a pharmacy licence. All licenced pharmacies were classified as 'chain' ( $\geq 5$ retail stores in Massachusetts) or 'non-chain' $(<5$ retail stores in Massachusetts) pharmacies, and the proportion of chain and non-chain pharmacies possessing a tobacco licence were determined. $\chi^{2}$ test was used to test for a difference between the proportion of chain and non-chain pharmacies possessing a tobacco licence.

Pharmacies possessing a tobacco licence were randomly selected for a telephone survey conducted in March-April 2010 to determine the availability of tobacco and non-prescription NRT products. A $10 \%$ subset $(n=70)$ was desired. Pharmacies were randomised by the following procedure. First, all licenced pharmacies possessing a tobacco licence were listed in an electronic spreadsheet. Next, a random number generator was used to assign a random number to each pharmacy. The list of pharmacies was then sorted by random number to create a list of pharmacies in random order. Pharmacies were contacted in successive chronological order, according to the randomised list. Fisher's exact test was used to test for a difference between the proportion of chain and non-chain pharmacies within the sample that possess a tobacco licence. Figure 1 illustrates the sampling strategy used.

Pharmacies were contacted via telephone. Interviewers identified themselves, stated the survey's purpose and nature and invited pharmacy staff to participate. No participant incentive was provided. Interviews were administered to store clerks, managers or pharmacists to determine product and service availability. The availability of the following types of tobacco products was determined: cigarettes, cigars, little cigars/cigarillos (small and mid-sized cigars), pipe tobacco, moist snuff (smokeless tobacco product typically placed between the lower lip and gum), snus (Swedish-styled smokeless tobacco product

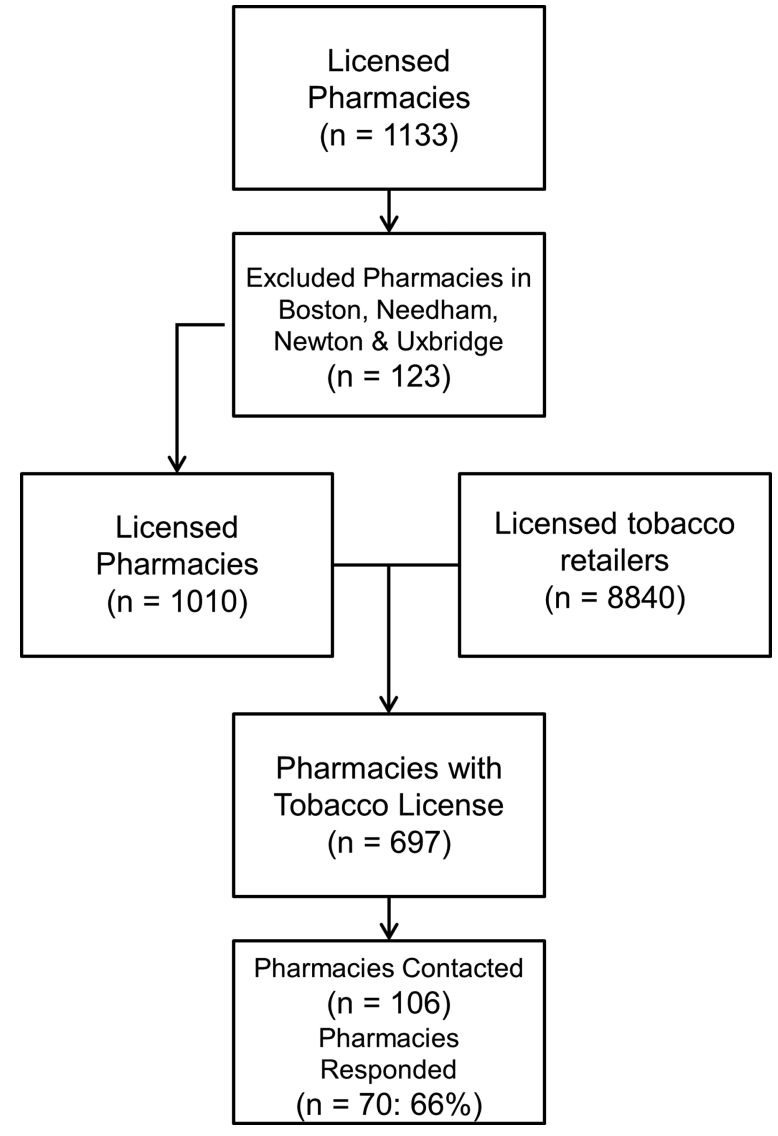

Figure 1 Flow diagram of pharmacy sample selection.

typically placed between the upper lip and gum), roll-your-own tobacco (RYO; pouched tobacco used for making cigarettes by hand or with a device), dissolvable tobacco (small tobacco tablets that dissolve in the mouth) and electronic cigarettes (battery powered devices that vapourise a nicotine solution within a cartridge). Descriptions of each type of product and examples of leading brands were provided to help respondents distinguish between tobacco product types and quickly determine availability. The Harvard School of Public Health Office of Human Research Administration deemed the study protocol as exempt, and not subject to review.

\section{RESULTS}

Out of the 1133 licenced pharmacies in Massachusetts, 787 possessed a licence to sell tobacco products (69.5\%). Pharmacies with a tobacco licence represented $9 \%$ of all licenced tobacco retailers in Massachusetts. After excluding pharmacies located within the communities that had adopted tobacco-free pharmacy policies, 697 pharmacies possessed a tobacco licence (69.0\%). These pharmacies represented $8 \%$ of the state's licenced tobacco retailers. Among the pharmacies with a tobacco licence, $80 \%$ were chain pharmacies. A significantly higher proportion of chain pharmacies $(70 \%)$ had a licence to sell tobacco products compared with non-chain pharmacies $(24 \%$; $p<0.001)$.

To achieve the desired sample of 70 pharmacies $(10 \%$ subset of pharmacies possessing a tobacco licence), 106 pharmacies were contacted (66\% response rate). While all pharmacies interviewed by phone possessed a tobacco licence, 90\% $(n=63)$ reported current sale of tobacco products. Within the sample, $89 \%(n=62)$ of pharmacies were chain pharmacies, $11 \%(n=8)$ were non-chain pharmacies. Further, $97 \%$ of chain pharmacies 
reported selling tobacco products compared with 38\% (ie, 3/8) of non-chain pharmacies $(p<0.001)$. Out of all the respondents, $41.9 \%$ were pharmacists, $10.8 \%$ were pharmacy managers, $11.8 \%$ were pharmacy technicians, $2.2 \%$ were pharmacy interns, $18.3 \%$ were store clerks, $6.5 \%$ were store supervisors, $7.5 \%$ were store managers and $1.1 \%$ were store owners.

Among those pharmacies reporting tobacco product sales, cigarettes were available for purchase in $100 \%$ of pharmacies. Cigars were the next most available product (69\%), followed by little cigars/cigarillos (66\%), moist snuff (53\%), pipe tobacco (49\%), RYO tobacco (34\%), snus (14\%), dissolvable tobacco $(11 \%)$ and electronic cigarettes $(2 \%)$.

Nicotine patch (100\%), nicotine gum (100\%) and nicotine lozenge (98\%) were available in nearly all pharmacies which sold tobacco products. Figure 2 displays the availability of tobacco products, and NRT products among pharmacies selling tobacco.

\section{DISCUSSION}

A majority (69\%) of pharmacies in Massachusetts was licenced to sell tobacco products, and pharmacies made up $9 \%$ of tobacco retailers. In addition, a wide variety of tobacco products were being sold in Massachusetts pharmacies, including many non-cigarette products, such as cigars, little cigars/cigarillos, moist snuff and pipe tobacco. In recent years, sales of noncigarette tobacco products, including smokeless tobacco and little cigars, have increased. ${ }^{25}$ Little cigars/cigarillos and moist snuff were found in $66 \%$ and $53 \%$ of pharmacies, respectively. Further, many new tobacco products have recently been introduced into US markets, including snus and electronic cigarettes. New products were sold in less than $15 \%$ of pharmacies.

Among the pharmacies contacted, 10\% reported not selling tobacco products. We excluded pharmacies located within communities that, at the time of data collection, had laws prohibiting pharmacy tobacco sales. Therefore, it is assumed that the contacted pharmacies were voluntarily abstaining from tobacco product sales, despite possessing a tobacco licence. It is possible that some pharmacies may have elected to cease tobacco product sales as a business decision or out of anticipation of future sales restrictions. In California, voluntary abandonment of tobacco products sales by pharmacies has been reported. ${ }^{26}$

The finding that a greater proportion of chain pharmacies possessed a tobacco licence (97\%) compared with non-chain pharmacies $(38 \%)$ is consistent with previous reports. ${ }^{20-23} 27$ For instance, Hickey and colleagues examined tobacco and pharmacy licences in Iowa and found that chain pharmacies were
34 times more likely to sell tobacco products, compared with independent pharmacies. ${ }^{27}$ Chain pharmacies likely follow a corporate structure and may be less able to make decisions regarding tobacco product sales within individual stores, compared with independent pharmacies. Among the sample of pharmacies contacted, only two chain pharmacies reported not selling tobacco products.

Previous research has revealed a significant association between tobacco retailer density and youth smoking. ${ }^{28}$ Further, proximity to tobacco retailers has been shown to influence smoking abstinence among smokers motivated to quit. ${ }^{29}$ Removal of tobacco sales from Massachusetts pharmacies, which make up nearly $10 \%$ of tobacco retailers in the state, might directly reduce the density and proximity of tobacco retailers to youth and adult smokers. Therefore, potential public health benefits may be realised through the adoption of tobacco-free pharmacy policies. However, no studies to date have investigated the impact of tobacco sales restrictions in pharmacies on smoking behaviour and initiation. Further research should also investigate pharmacists' knowledge of alternative tobacco products. Because these products are available for sale within pharmacies, pharmacists should be trained in discussing the potential risks of these products.

Massachusetts has been a leader in implementing effective tobacco control policies and has one of the nation's lowest smoking rates. ${ }^{30} 31$ Consequently, this study's findings may not be generalisable to the rest of the USA. Pharmacies which declined to participate may have differed from the analytical sample, creating a potential sampling bias. Further, the definition used for chain pharmacy (five or more stores in Massachusetts) may have resulted in some pharmacies being misclassified (eg, national chain pharmacies being classified as non-chains). This definition was used because it has been used elsewhere for enforcing tobacco control policies. ${ }^{32}$ Finally, telephone interview data were not independently verified. However, the survey strategy used enabled the collection of data from a random sample of pharmacies located throughout Massachusetts.

\section{CONCLUSION}

Since completion of this study, several additional communities in Massachusetts have adopted tobacco-free pharmacy policies (personal correspondence (AS), Municipal Tobacco Control Technical Assistance Program). In Massachusetts, instituting tobacco-free pharmacy laws would impact a majority of pharmacies, resulting in the removal of a variety of tobacco
Figure 2 Availability of tobacco products and NRT products in Massachusetts pharmacies selling tobacco.

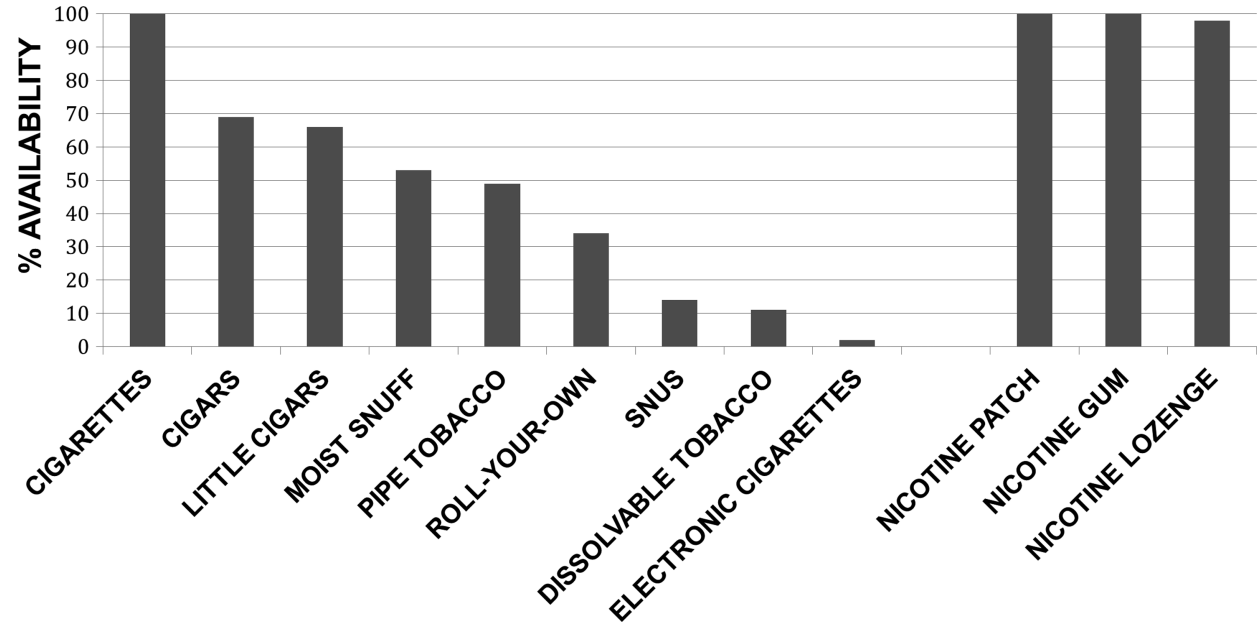




\section{What this paper adds}

- Despite a growing number of communities adopting tobaccofree pharmacy policies, little is known regarding the scope of pharmacy involvement in the tobacco market.

- This study found that tobacco-free pharmacy policies stand to affect a majority of Massachusetts pharmacies and nearly one in ten tobacco retailers. Further, a wide variety of tobacco products, including cigarettes, cigars, little cigars/ cigarillos, moist snuff and pipe tobacco, are currently being sold in pharmacies.

products from their shelves. Further, nearly one in ten tobacco retailers would be eliminated by prohibiting tobacco sales in pharmacies in Massachusetts statewide. Publicly available data, such as pharmacy and tobacco retailer registration, can be used to estimate the scope of state-level involvement of pharmacies in the tobacco retail sector. These data from the USA contrast markedly with the prevailing situation in most countries, where voluntary or tobacco sales bans in pharmacies are the norm. Indeed, one predicted future trend for tobacco control may see pharmacies designated as the sole conveyor of tobacco products, under a system of highly restricted sale. ${ }^{33}$ Until such time, further research is needed to understand the impact on smoking initiation and maintenance that new tobacco-free pharmacy policies will have in jurisdictions in which they are introduced.

Contributors AS and VR conceived the research and design. WH, JL and JN collected all data and analysed the data. All authors contributed to writing and revision of the manuscript.

Competing interests None

Ethics approval The Harvard School of Public Health's Office for Human Research Administration exempted this study from review.

Provenance and peer review Not commissioned; externally peer reviewed.

Data sharing statement Data will be made available to qualified researchers upon application to the corresponding author.

\section{REFERENCES}

1. Physicians for a Smoke Free Canada. Tobacco free pharmacies. http://www. smoke-free.ca/pdf 1/pharmacy-backgrounder.pdf(accessed 3 0ct 2012).

2. Quality Care Pharmacy Program. Pharmacy stock (STO-5). Canberra: The Pharmacy Guild of Australia, 2004.

3. Fincham JE. An unfortunate and avoidable component of American pharmacy: tobacco. Am J Pharm Educ 2008;72:57.

4. Viteri E, Barnoya J, Hudmon KS, et al. Smoking cessation medications and cigarettes in Guatemala pharmacies. Tob Control 2012;21:477-81.

5. Katz MH. Banning tobacco sales in pharmacies: the right prescription. JAMA 2008;300:1451-3.

6. Boston Public Health Commission Regulation Restricting the Sale of Tobacco Products in the City of Boston. 2008. http://www.bphc.org/ boardofhealth/regulations/Forms\%20\%20Documents/regs TobaccoRestriction Regulation_12-11-08.pdf (accessed 25 Sep 2012).
7. Smoking Cessation Products-US-March 2010, Mintel. http://store.mintel. com/smoking-cessation-products-us-march-2010.html (accessed 3 Oct 2012).

8. Centers for Disease Control and Prevention. Smoking-attributable mortality, morbidity, and economic costs (SAMMEC). https://apps.nccd.cdc.gov/sammec/ index.asp (accessed 25 Sep 2012).

9. CVS Minute Clinic. http://www.minuteclinic.com/ (accessed 25 Sep 2012).

10. Walgreens Take Care Clinic. http://www.walgreens.com/topic/clinic/ take-care-walgreens-clinics.jsp (accessed 25 Sep 2012).

11. Bock BC, Hudmon KS, Christian J, et al. A tailored intervention to support pharmacy-based counseling for smoking cessation. Nicotine Tob Res 2010;12:217-25.

12. Anon. Committee reports. J Am Pharm Assoc 1971;NS11:270.

13. Mertinez PJ, Knapp J, Kottke TE. Beliefs and attitudes of Minnesota pharmacists regarding tobacco sales and smoking cessation counseling. Tob Control 1993;2:306-10.

14. Davis RM. Tobacco sales in pharmacies: mixing good drugs and bad drugs. Tob Control 1992;1:84-6.

15. Hudmon KS, Hussar DA, Fenlon CM, et al. Pharmacy students' perceptions of tobacco sales in pharmacies and suggested strategies for promoting tobacco-free experiential sites. Am J Pharm Educ 2006;70:75.

16. Kotecki JE, Hillery DL. A survey of pharmacists' opinions and practices related to the sale of cigarettes in pharmacies-revisited. J Community Health 2002;27:321-33.

17. Hudmon KS, Fenlon CM, Corelli RL, et al. Tobacco sales in pharmacies: time to quit. Tob Control 2006;15:35-8.

18. Hudmon KS, Prokhorov AV, Corelli RL. Tobacco cessation counseling: pharmacists opinions and practices. Patient Educ Couns 2006;61:152-60.

19. American Pharmacists Association. http://www.pharmacist.com/AM/Template $\mathrm{cfm}$ ?Section $=$ News Releases2\&Template $=/ \mathrm{CM} /$ ContentDisplay.cfm\&ContentID = 23367 (accessed 25 Sep 2012).

20. Bentley JP, Banahan BF 3rd, McCaffrey DJ 3rd, et al. Sale of tobacco products in pharmacies: results and implications of an empirical study. J Am Pharm Assoc 1998;38:703-9

21. Kotecki JE, Fowler JB, German TC, et al. Kentucky pharmacists' opinions and practices related to the sale of cigarettes and alcohol in pharmacies. J Community Health 2000;25:343-55

22. Eule B, Sullivan MK, Schroeder SA, et al. Merchandising of cigarettes in San Francisco pharmacies: 27 years later. Tob Control 2004;13:429-32.

23. Corelli RL, Aschebrook-Kilfoy B, Kim G, et al. Availability of Tobacco and Alcohol Products in Los Angeles Community Pharmacies. J Community Health 2012;37:113-18.

24. Seidenberg $\mathbf{A B}$, Behm I, Rees $\mathrm{WW}$, et al. Cigarette sales in pharmacies in the U.S.A. (2005-2009). Tob Control 2011;21:509-10.

25. Connolly GN, Alpert HR. Trends in the use of cigarettes and other tobacco products, 2000-2007. JAMA 2008;299:2629-30.

26. McDaniel PA, Malone RE. Why California retailers stop selling tobacco products, and what their customers and employees think about it when they do: case studies. BMC Public Health 2011;11:848.

27. Hickey LM, Farris KB, Peterson NA, et al. Predicting tobacco sales in community pharmacies using population demographics and pharmacy type. J Am Pharm Assoc 2006;46:385-80.

28. Novak SP, Reardon SF, Raudenbush SW, et al. Retail tobacco outlet density and youth cigarette smoking: a propensity-modeling approach. Am J Public Health 2006; 96 :670-6.

29. Reitzel LR, Cromley EK, Li Y, et al. The effect of tobacco outlet density and proximity on smoking cessation. Am J Public Health 2011;101:315-20.

30. Koh HK, Judge CM, Robbins $\mathrm{H}$, et al. The first decade of the Massachusetts Tobacco Control Program. Public Health Rep 2005;120:482-95.

31. Centers for Disease Control and Prevention. State-specific prevalence of cigarette smoking and smokeless tobacco use among adults_-United States, 2009. MMWR 2010;59:1400-6.

32. An Act Concerning Chain Store Cigarette Distributors. Public Act No. 11-37, State of Connecticut (2011).

33. Daube M. Banning cigarettes: the next step. http://www.sbs.com.au/news/article/ 1685025/Banning-cigarettes:-The-next-step (accessed 25 Sep 2012). 